\title{
A construção do pensamento transdisciplinar na sociedade em rede
}

DOI: http://dx.doi.org/10.20435/multi.v23i55.2187

Entender a filosofia de um periódico de caráter multidisciplinar implica conhecer a construção da transdisciplinaridade (WEIL, 1993; SOMMERMAN, 2006), no contexto de uma sociedade estruturada em redes. Essa tarefa começa pelo que se entende por disciplina ou matéria propriamente dita, como muitos afirmam na academia. Nessa dimensão, a disciplina ou matéria constitui um conjunto de conteúdos ordenados e sequenciais, implicando uma tratativa baseada em procedimentos que permitem ir e vir no exercício de compreensão de sua lógica, o que pode ser denominado de disciplinaridade. Entende-se que isso constitui a episteme em si, desse conjunto passível de compreensão.

Essa episteme disciplinar ou disciplinaridade pode evoluir para a intradisciplinaridade, multidisciplinaridade, interdisciplinaridade e transdisciplinaridade. A intradisciplinaridade consiste nas relações internas da disciplina, que compreendem estrutura lógica, histórico, avanços e atualizações, aplicações diretas e indiretas na realidade quer concreta, real, quer abstrata.

A multidisciplinaridade implica a atuação de várias disciplinas (epistemes) sobre o mesmo objeto/sujeito, representando um somatório que pode se revelar como conflitos epistemológicos. Como dito, a multidisciplinaridade pode evoluir em termos de aprofundamento para a dimensão da interdisciplinaridade (JANTSCH; BIANCHETTI, 1995) na qual haverá sempre a tentativa de superação do processo de abstração desarticulada do conhecimento, com ênfase na articulação epistemológica, o que permite afirmar em termos de academia que :

1. A pesquisa (espírito de investigação) é mais importante que a aula;

2. A aula deve ser um produto de construção coletiva, cujo foco é a aprendizagem articulada e integrada;

3. O estudante deve ser o protagonista responsável pela sua própria aprendizagem significativa; 
4. A avaliação do processo de produção e assimilação do conhecimento deve se dar passo a passo; e

5. O currículo nesse contexto deve representar um conjunto libertador de oportunidades na formação de indivíduos atuantes na sociedade.

A continuar a sequência de entendimento, vê-se que a interdisciplinaridade pode evoluir em amplitude e profundidade para a transdisciplinaridade (ANTÔNIO, 2002; ROCHA FILHO, 2007), que é a busca de uma nova compreensão da realidade entre e para além das disciplinas - é uma abordagem que passa entre, além e através das disciplinas na busca de compreensão da complexidade.

A UNESCO (1994) fez publicar uma Carta na qual afirma que a transdisciplinaridade:

1. Não procura o domínio sobre várias outras disciplinas, mas a abertura de todas elas àquilo que as atravessa e as ultrapassa (Art. 3으)

2. Não constitui uma nova filosofia nem uma nova metafísica nem uma ciência das ciências (Art. 70)

3. Implica a formação de profissionais cada vez mais completos, compatíveis com as exigências do mundo do trabalho com um pensamento organizador (pensamento complexo).

Por outro lado, é possível considerar o pensamento interdisciplinar na construção da transdisciplinaridade a partir do pensamento de Philippi Jr. e Silva Neto (2011), quando afirmam que a discussão do tema interdisciplinaridade inscreve-se no amplo movimento de reflexão crítica sobre o tipo de avanço da ciência e da tecnologia no mundo moderno, associado ao que se conhece como tecnociência. Trata-se de repensar suas implicações no homem e no planeta, em razão da ambivalência de seus resultados, que trazem benefícios, mas também riscos.

O acima exposto justifica a presença de trabalhos científicos de diferentes áreas do conhecimento na Revista Multitemas, permitindo que os seus leitores possam serpentear em diferentes abordagens e quiçá fazerem as devidas conexões, o que somaria com o pensamento de que a sociedade cada vez mais se estrutura em redes tecidas de fios de muitas naturezas, caracterizando os matizes multi e interdisciplinares. Os temas apresenta- 
dos abordam questões tais como: 1) variáveis climáticas com os casos de dengue; 2) qualidade de vida em cuidadores de crianças e adolescentes; 3) Logística reversa; 4) Parque Municipal: uma proposta de reestruturação do circuito de trilhas; 5) Zoonoses; 6) Ecodesarrollo como estrategia para la sostenibilidad; 7) citotoxicidade e genotoxicidade de Hibiscus sabdariffa; 8) Cooperativismo agropecuário; 9) equoterapia como ferramenta psicopedagógica, 10) eficácia das oficinas de pesquisa e produção textual na iniciação científica; 11) Importância socioeconômica da mandioca) 12) direito à educação da pessoa com deficiência; 13) Cultivo de Oreochromis niloticus; 14) Risco nutricional em pacientes hospitalizados e 15) Ecodesarrollo como estrategia para la sostenibilidad.

Igualmente, a abordagem da construção da transdisciplinaridade relacionada com as concepções da sociedade em rede traz a relevância de outro modo de fazer ciência, qual seja, o de produzir conhecimento de modo interativo e integrativo, a partir justamente dos nós de intersecção dos distintos saberes em que os dados estruturados e mensuráveis de modo objetivo circulam paralelamente aos Big Data, passíveis de apreciação apenas de modo subjetivo. Castells (2017) analisa toda essa situação e afirma que as comunidades on-line estão se desenvolvendo muito rapidamente não como um mundo virtual mas como virtualidade real integrada a outras formas de interação em uma vida cotidiana cada vez mais híbrida.

A consequência do acima exposto, que se manifesta de modo crescente, é a necessidade de se perceber a sociedade e, por conseguinte, a ciência não de modo segmentado, mas com a visão interdisciplinar na construção do entrelaçamento das epistemes na dimensão transdisciplinar.

Campo Grande, MS, outubro de 2018.

Prof. Dr. Heitor Romero Marques

Editor 


\section{REFERÊNCIAS}

ANTÔNIO, S. Educação e transdisciplinaridade. Rio de Janeiro: Lucerna, 2002.

CASTELLS, M. A sociedade em rede. 18.ed. São Paulo: Paz \& Terra, 2017.

JANTSCH, A. P.; BIANCHETTI, L. (Org.). Interdisciplinaridade: para além da filosofia do sujeito. 4. ed. Petrópolis, RJ: Vozes, 1995.

ROCHA FILHO, J. F. Transdisciplinaridade: a natureza íntima da educação científica.

Porto Alegre: EDIPUCRS, 2007.

SOMMERMAN, A. Inter ou transdisciplinaridade? São Paulo: Paulus, 2006.

UNESCO. Carta da transdiciplinaridade, 1994.

WEIL, P. Rumo à nova transdisciplinaridade. São Paulo: Sumus, 1993. 